\title{
Congenital malformations in sub-Saharan Africa-warnings of a silent epidemic?
}

\author{
Ali Sié, *Johanna Hanefeld, Mike Chaponda, R Matthew Chico, Kirsty LeDoare, \\ Philippe Mayaud, Jan Felix Drexler, Thomas Jaenisch
}

SARS-CoV-2 has tragically shown the cost of a global pandemic. Only a few years earlier, the outbreak of Zika virus in Brazil and elsewhere in South America caught the international community by surprise. There was no epidemiological surveillance for Zika virus established at the time, since the African-origin virus was previously endemic in Africa and Asia only; clinicians either failed to notify authorities of suspected cases, or reported Zika, dengue, and chikungunya infections in parallel, with limited diagnostic facilities available to differentiate between them. ${ }^{1} \mathrm{~A}$ lack of common understanding about diagnosis and symptoms produced different case definitions and a wide range of case estimates; ${ }^{2}$ early estimates of the risk of microcephaly varied across Brazil. ${ }^{3}$ These challenges delayed meaningful epidemiological interpretations and probably contributed to an increase in unsafe abortion $s^{4}$ and pregnancy delays ${ }^{5}$ throughout Latin America for fear of the Zikaassociated complications.

Intensive global research established beyond doubt the association between maternal Zika virus infection and congenital malformations. ${ }^{6,7}$ However, we do not know if this association is unique to the Latin American outbreak and virus lineage, or whether similar symptoms occur elsewhere; and to what extent congenital malformations associated with Zika virus or other infections are present in Asia and Africa.

In sub-Saharan Africa, surveillance data for both congenital malformations and laboratory diagnostics of Zika and related viruses are largely unavailable. ${ }^{8}$ Regardless, observed reintroduction of the Latin American outbreak lineage into Angola ${ }^{9}$ underscores a pressing question: what are, or will be, the spectrum of clinical manifestations of Zika virus infections in sub- Saharan Africa? Would we be able to detect a signal of Zika virus-induced decreased head circumference or even microcephaly? In Latin America, the standards produced by Estudio Colaborativo Latino Americano de Malformaciones Congenitas were instrumental to detect the signal of microcephaly at an early stage. Data from two African countries (Côte d'Ivoire and Cameroon) show a large variability in head circumference without the presence of Zika virus-induced microcephaly. ${ }^{10}$

In addition, the origin of the Latin American Zika outbreak remains poorly understood and longer-term consequences of various vector-borne diseases, including chikungunya and dengue, on maternal health and child development are only partly understood. ${ }^{11,12}$ 
To address gaps in knowledge, we need to improve our understanding of the epidemiology and aetiology of congenital malformations and develop better tools for diagnosis, management, and prevention of infection-related causes in sub-Saharan Africa. ${ }^{11}$

We therefore call for greater and more comprehensive action in research, capacity building, and development of a public health approach to congenital abnormalities in subSaharan Africa. Recent investments in surveillance and diagnostic capacity as part of the COVID-19 pandemic response could serve as a catalyst for greater attention on arboviruses as well.

The immediate aim should be to provide decision makers with a baseline frequency of congenital abnormalities, which is granular enough to account for regional variability. This baseline includes the simple routine measurement of head circumference at birth, which would allow detection of microcephaly. Of equal importance is strengthening health system responses to children who are born with congenital abnormalities in sub-Saharan Africa to ensure that new knowledge on the public-health burden goes hand in hand with the development of services and interventions to improve health and wellbeing of parents and affected children.

Beyond the immediate benefit of preparedness for potential Zika epidemics in subSaharan Africa, such work is of great importance for achieving universal health coverage and improving maternal and child health.

\footnotetext{
* Corresponding author

HanefeldJ@rki.de
}

National Institute of Public Health, Burkina Faso (AS); Department of Global Health and Development, London School of Hygiene and Tropical Medicine, London, UK (JH, RMC, PM); Zentrum Internationaler Gesundheitsschutz; Robert Koch Institute, Berlin 14195, Germany (JH); Tropical Diseases Research Centre, Ndola, Zambia (MC); Paediatric Infectious Diseases Research Group, St George's Medical School, London, UK (KL); Charité-Universitätsmedizin Berlin Universität Berlin, Humbolt-Universität zu Berlin, Berlin, Germany (JFD); Institute of Virology, Berlin, Germany (JFD); Heidelberg Institute of Global Health (HIGH), Heidelberg University Hospital, Heidelberg, Germany (TJ); Center for Global Health, Colorado School of Public Health, Aurora, CO, USA (TJ)

\section{References}

${ }^{1}$ Fischer C, Drosten C, Drexler JF. The difficulties in obtaining reliable Zika virus diagnostics. Lancet Infect Dis 2019; 19: 240-41.

2 Victora CG, Schuler-Faccini L, Matijasevich A, Ribeiro E, Pessoa A, Barros FC. Microcephaly in Brazil: how to interpret reported numbers? Lancet 2016; 387: 621-24.

${ }^{3}$ Jaenisch T, Rosenberger KD, Brito C, Brady O, Brasil P, Marques ET. Risk of microcephaly after Zika virus infection in Brazil, 2015 to 2016. Bull World Health Organ 2017; 95: 191-98.

${ }^{4}$ Aiken AR, Scott JG, Gomperts R, Trussell J, Worrell M, Aiken CE. Requests for abortion in Latin America related to concern about Zika Virus exposure. N Engl J Med 2016; 375: 396-98. 
${ }^{5}$ Castro MC, Han QC, Carvalho LR, Victora CG, França GVA. Implications of Zika virus and congenital Zika syndrome for the number of live births in Brazil. Proc Natl Acad Sci USA 2018; 115: 6177-82.

${ }^{6}$ Brady OJ, Osgood-Zimmerman A, Kassebaum NJ, et al. The association between Zika virus infection and microcephaly in Brazil 2015-2017: an observational analysis of over 4 million births. PLoS Med 2019; 16: e1002755.

${ }^{7}$ Coyne CB, Lazear HM. Zika virus - reigniting the TORCH. Nat Rev Microbiol 2016; 14: 70715.

${ }^{8}$ Yuan L, Huang XY, Liu ZY, et al. A single mutation in the prM protein of Zika virus contributes to fetal microcephaly. Science 2017; 358: 933-36.

${ }^{9}$ Hill SC, Vasconcelos J, Neto Z, et al. Emergence of the Asian lineage of Zika virus in Angola: an outbreak investigation. Lancet Infect Dis 2019; 19: 1138-47.

${ }^{10}$ Funk A, Jayaratne K, Tejiokem MC, et al. High baseline prevalence of microcephaly in Zikaepidemic and non-epidemic regions: data from sub-Saharan Africa, Asia, and the Antilles. International Symposium on Zika Virus Research; Marseille, France; June 4-6, 2018.

${ }^{11}$ Ashwal S, Michelson D, Plawner L, Dobyns WB. Practice parameter: evaluation of the child with microcephaly (an evidence-based review): report of the Quality Standards Subcommittee of the American Academy of Neurology and the Practice Committee of the Child Neurology Society. Neurology 2009; 73: 887-97.

${ }^{12}$ Charlier C, Beaudoin MC, Couderc T, Lortholary O, Lecuit M. Arboviruses and pregnancy: maternal, fetal, and neonatal effects. Lancet Child Adolesc Health 2017; 1: 134-46. 